\title{
HUBUNGAN TINGKAT PENGETAHUAN PERAWAT DENGAN PENERAPAN UNIVERSAL PRECAUTION PADA PERAWAT DI BANGSAL RAWAT INAP RUMAH SAKIT PKU MUHAMMADIYAH YOGYAKARTA
}

\author{
Yulianti, Rosyidah, Widodo Hariyono \\ Fakultas Kesehatan Masyarakat, Universitas Ahmad Dahlan, Yogyakarta
}

\begin{abstract}
Background: Universal Precaution is common caution which is nursing must be obeyed by nurse or medical labor in doing every nursing action towards the patient to protect from some of infection material. The nurse's knowledge about the universal precaution is needed to be high on guard towards spreading disease. This research purposes to know the relation between nurse's knowledge in application universal precaution in PKU Muhammadiyah Yogyakarta hospital.

Method: This was an observational analytic with research using cross sectional approach. The population in this research is the nurse in patient II and III classes amounted to 34 nurses. The sample taken by total sampling technique is number of 34 nurses. The data of research is taken by observation and spreading question and processed by using the chi square test.

Result: The degree of nurse's knowledge in hospital categorize high amounted to be 26 nurses by percentage of $76,47 \%$. (1) the degree of nurse's knowledge in application wash hand to the nurse categorize good amounted by percentage of $79,41 \%$, gotten the score $p=0,019$, it means that there is a significant relation between the degree of nurse's knowledge with the application of wash hand to the nurse in hospitalized ward of PKU Muhammadiyah Yogyakarta hospital (2) the degree of nurse's knowledge with application of antiseptic use and the disinfectant to the nurse categorize good amounted by percentage of $82,35 \%$, gotten the score $p=0,006$, it means that there is a significant relation between the degree of nurse's knowledge with the application of antiseptic use and the disinfectant to the nurse in PKU Muhammadiyah Yogyakarta hospital. (3) The degree of nurse's knowledge with the application the use of self protector to the nurse categorize good amounted by percentage of $85,29 \%$, gotten the score $p=$ 0,037 , means that there is a significant relation between the degree of nurse's knowledge with application of self protector use to the nurse in the PKU Muhammadiyah Yogyakarta hospital. (4) the degree of nurse's knowledge with the application the discharge of medical rubbish to the nurse categorize good amounted by percentage of $85,29 \%$, gotten the score $p=0,001$, means there is a significant relation between the degree of nurse's knowledge with the application of medical rubbish discharge to the nurse in PKU Muhammadiyah Yogyakarta hospital.

Conclusion: There was a significant relationship between the degree of nurse's knowledge with application universal precaution to the nurse in patient in PKU Muhammadiyah Yogyakarta hospital.
\end{abstract}

Key word: the nurse, the degree of knowledge, nosocomial infection, universal precaution

\section{PENDAHULUAN}

Rumah sakit (RS) sebagai institusi pelayanan kesehatan, di dalamnya terdapat bangunan, peralatan, manusia (petugas, pasien, dan pengunjung) serta kegiatan pelayanan kesehatan. Selama 10-20 tahun belakang ini telah banyak perkembangan yang telah dibuat untuk mencari masalah utama terhadap meningkatnya angka kejadian infeksi nosokomial dibanyak negara, dan dibeberapa negara, kondisinya justru sangat memprihatinkan. ${ }^{1}$

Salah satu strategi yang sudah terbukti bermanfaat dalam upaya pengendalian infeksi nosokomial adalah dengan meningkatkan kemampuan petugas kesehatan dalam menjalankan metode Universal Precaution atau yang dalam istilah Indonesia dikenal dengan kewaspadaan universal. Kewaspadaan universal 
merupakan suatu cara penanganan baru untuk meminimalkan pajanan darah dan cairan tubuh dari semua pasien tanpa memperdulikan status infeksi. Pencegahan penularan infeksi nosokomial dengan pemutusan rantai penularan pada jalan masuk (portal of entry) dilakukan dengan memperhatikan teknik aseptik pada setiap tindakan terhadap pasien. ${ }^{2}$

Rumah Sakit PKU Muhammadiyah adalah rumah sakit yang telah ter ISO 9001 -2000. Rumah sakit ini mempunyai visi dan misi sebagai pelaksana pelayanan prima dalam Bidang kesehatan yang sesuai dengan standar pelayanan dan mewujudkan pengembangan pelayanan perumahsakitan dan manajemen rumah sakit yang memuaskan. Rumah sakit yang baik, tentu harus ditunjang oleh fasilitas yang baik,lengkap dan memadai. Sebagai rumah sakit yang telah mendapatkan label ISO, rumah sakit tersebut memberikan pelayanan kuratif, rehabilitatif,preventif, dan promotif serta menjadi tempat rujukan dan tempat penelitian dalam pengembangan ilmu dan teknologi kesehatan. ${ }^{3}$

\section{METODE PENELITIAN}

Penelitian ini menggunakan metode analitik observasional, dengan menggunakan rancangan potong lintang (cross sectional).

\section{A. Populasi dan Sampel}

Populasi dan sampel dalam penelitian ini berjumlah 34 tenaga perawat, karena menggunakan teknik total sampling maka semua populasi dijadikan sampel penelitian

\section{B. Pengumpulan Data}

1) Data Primer

a) Data langsung diambil dari responden dengan menggunakan kuesioner untuk mengetahui tingkat pendidikan serta pengetahuan perawat tentang universal precaution.

b) Melakukan observasi langsung untuk mengetahui sikap dan prosedur kerja perawat dalam penerapan universal precaution di RS PKU Muhammadiyah, Yogyakarta.

2) Data Sekunder

Data yang didapatkan dari lokasi penelitian yaitu mengenai gambaran umum standar universal precaution beserta prosedur kerja yang dijalankan oleh perawat di RS PKU Muhammadiyah, Yogyakarta.

\section{Analisis Data}

1) Analisis univariate dengan menyajikan distribusi frekuensi dari variabelvariabel yang diteliti. Analisis ini digunakan untuk memperoleh gambaran pada masing-masing variabel yang diteliti dan disajikan dengan menggunakan tabel distribusi frekuensi.

2) Analisis bivariate yaitu menganalisis dua varibel yang diduga mempunyai hubungan atau berkolerasi. Uji statistik yang digunakan adalah $\mathrm{X}^{2}$ (chi square), apabila nilai $X^{2}$ (chi square) hitung $>X^{2}$ (chi square) tabel maka artinya ada hubungan yang signifikan antara variabel bebas dengan variabel terikat.

\section{HASIL DAN PEMBAHASAN}

4.
A. Hasil Penelitian
B.
1) Karakteristik Responden 
Tabel 1. Distribusi Frekuensi Responden Berdasarkan Jenis Kelamin dan Tingkat Pendidikan di Bangsal Raudhah, Multazam dan Arofah RS PKU Muhammadiyah Yogyakarta Tahun 2009

\begin{tabular}{clcc}
\hline No. & Karakteristik Responden & Frekuensi (n) & Persentase (\%) \\
\hline 1 & Jenis kelamin & 5 & 14,7 \\
& $\begin{array}{l}\text { a. Laki-laki } \\
\text { b. Perempuan }\end{array}$ & 29 & 85,3 \\
\hline \multirow{2}{*}{ Jumlah } & 34 & 100 \\
\hline 2 & Tingkat pendidikan & 3 & \\
a. SPK & 19 & 8,8 \\
b. D3 Keperawatan & 12 & 55,9 \\
& c. S1 Keperawatan & 34 & 35,3 \\
\hline & Jumlah & & 100 \\
\hline
\end{tabular}

Karakteristik perawat atau responden pada tabel 4.2 diketahui bahwa responden di Bangsal Raudhah, Multazam dan Arafah RS PKU Muhammadiyah Yogyakarta berdasarkan jenis kelamin perempuan sejumlah 29 perawat $(85,3 \%)$ dan perawat yang berjenis kelamin laki-laki sejumlah 5 orang $(14,7 \%)$. Sebagian perawat berjenis kelamin perempuan. Berdasarkan tabel di atas didapatkan bahwa sebagian besar perawat berpendidikan terakhir D3 Keperawatan sejumlah 19 perawat $(55,9 \%)$, perawat dengan pendidikan terakhir S1 sejumlah 9 perawat $(26,5 \%)$, dan pendidikan terakhir SPK sejumlah 6 perawat $(17,6 \%)$.

\section{2) Analisis Univariat}

Tabel 2. Distribusi Responden Berdasarkan Pengamatan Terhadap Perawat yang Cuci Tangan di Bangsal Rawat Inap RS PKU Muhammadiyah Yogyakarta

\begin{tabular}{lcc}
\hline Cuci tangan & Frekuensi & Persentase (\%) \\
\hline Baik & 27 & 79,41 \\
\hline Cukup baik & 7 & 20,59 \\
\hline Total & 34 & 100,00 \\
\hline
\end{tabular}

Tabel 2 menunjukkan bahwa dari 34 responden yang memiliki perilaku cuci tangan yang baik berjumlah 27 perawat $(79,41 \%)$.

Tabel 3. Distribusi Responden Berdasarkan Pengamatan Terhadap Perawat yang Menggunakan Antiseptic dan Desinfektan di Bangsal Rawat Inap RS PKU Muhammadiyah Yogyakarta

\begin{tabular}{lccc}
\hline & Pengg.antiseptik \& desinfektan & Frekuensi & Persentase (\%) \\
\hline Baik & 28 & 82,35 \\
\hline Cukup baik & 6 & 17,65 \\
\hline Total & 34 & 100,00 \\
\hline
\end{tabular}

Tabel 3 menunjukkan bahwa dari 34 responden yang menggunakan antiseptik dan desinfektan dengan baik berjumlah 28 perawat $(82,35 \%)$. 
Tabel 4. Distribusi Responden Berdasarkan Pengamatan Perawat yang Menggunakan Alat Pelindung Diri di Bangsal Rawat Inap RS PKU Muhammadiyah Yogyakarta

\begin{tabular}{lll}
\hline \multicolumn{1}{c}{ Pengg. Alat Pelindung Diri } & Frekuensi & Persentase (\%) \\
\hline Baik & 29 & 85,29 \\
\hline Cukup baik & 5 & 14,71 \\
\hline Total & 34 & 100,00 \\
\hline
\end{tabular}

Tabel 4 menunjukkan bahwa dari 34 responden yang menggunakan alat pelindung diri dengan baik berjumlah 29 perawat $(85,29 \%)$.

Tabel 5. Distribusi Responden Berdasarkan Pengamatan Terhadap Perawat yang Menerapkan Pembuangan Sampah Medis Secara Aman di Bangsal Rawat Inap RS PKU Muhammadiyah Yogyakarta

\begin{tabular}{lll}
\hline \multicolumn{1}{c}{ Pengg. Alat Pelindung Diri } & Frekuensi & Persentase (\%) \\
\hline Baik & 28 & 82,35 \\
\hline Cukup baik & 6 & 17,65 \\
\hline Total & 34 & 100,00 \\
\hline
\end{tabular}

Tabel 5 menunjukkan bahwa dari 34 responden yang menggunakan alat pelindung diri dengan baik berjumlah 28 perawat $(82,35 \%)$.

\section{3) Analisis Bivariat}

a) Hubungan Tingkat Pengetahuan Perawat dengan Penerapan Cuci Tangan Perawat di Bangsal Rawat Inap RS PKU Muhammadiyah Yogyakarta

Tabel 6. Distribusi Frekuensi Responden Berdasarkan Variabel Penelitian Tingkat Pengetahuan Perawat dengan Penerapan Cuci Tangan Pada Perawat di Bangsal Rawat Inap RS PKU Muhammadiyah Yogyakarta 2009

\begin{tabular}{|c|c|c|c|c|c|c|c|}
\hline \multirow{3}{*}{$\begin{array}{c}\text { Tingkat } \\
\text { Pengetahuan }\end{array}$} & \multicolumn{4}{|c|}{ Cuci tangan } & \multirow{2}{*}{\multicolumn{2}{|c|}{ Total }} & \multirow{3}{*}{$P$ value } \\
\hline & \multicolumn{2}{|c|}{ Baik } & \multicolumn{2}{|c|}{ Cukup Baik } & & & \\
\hline & $\mathrm{N}$ & $\%$ & $\mathrm{~N}$ & $\%$ & $\mathrm{~N}$ & $\%$ & \\
\hline Tinggi & 23 & 67,6 & 3 & 8,8 & 26 & 76,5 & \\
\hline Sedang & 4 & 11,8 & 4 & 11,8 & 8 & 23,5 & 0,019 \\
\hline Total & 29 & 85,3 & 5 & 14,7 & 34 & 100 & \\
\hline
\end{tabular}

Berdasarkan hasil penelitian di Bangsal Rawat Inap RS PKU Muhamadiyah Yogyakarta, diketahui bahwa perawat dengan tingkat pengetahuan tinggi dengan penerapan cuci tangan yang baik sebanyak 23 perawat atau $67,6 \%$, sedangkan pada perawat yang tingkat pengetahuannya sedang dengan penerapan cuci tangan yang baik sebanyak 4 perawat atau $11,8 \%$. Perawat dengan tingkat pengetahuan tinggi dengan penerapan cuci tangan yang cukup baik sebanyak 3 perawat atau $8,8 \%$, sedangkan pada perawat yang tingkat pengetahuannya sedang dengan penerapan cuci tangan yang cukup baik sebanyak 4 perawat atau $11,8 \%$.

Berdasarkan hasil uji statistik antara dua variabel diperoleh nilai $p=0,019$, yang berarti nilai $p$ lebih besar dari alpha $(0,05)$, dengan demi- 
kian Ho ditolak dan Ha diterima, yang berarti ada hubungan yang signifikan antara tingkat pengetahuan perawat dengan penerapan cuci tangan pada perawat sebagai upaya pencegahan infeksi nosokomial di RS PKU Muhammadiyah Yogyakarta.

Tabel 7. Distribusi Frekuensi Responden Berdasarkan Variable Penelitian Tingkat Pengetahuan Perawat dengan Penggunaan Antiseptik dan Desinfektan Pada Perawat di Bangsal Rawat Inap RS PKU Muhammadiyah Yogyakarta 2009

\begin{tabular}{|c|c|c|c|c|c|c|c|}
\hline \multirow{4}{*}{$\begin{array}{c}\text { Tingkat } \\
\text { Pengetahuan }\end{array}$} & \multirow{2}{*}{\multicolumn{4}{|c|}{$\begin{array}{l}\text { Pengg.antiseptik\&desinfekt } \\
\text { an }\end{array}$}} & \multirow{3}{*}{\multicolumn{2}{|c|}{ Total }} & \multirow{4}{*}{$P$ value } \\
\hline & & & & & & & \\
\hline & \multicolumn{2}{|c|}{ Baik } & \multirow{2}{*}{$\frac{\text { Cukup }}{\mathrm{N}}$} & \multirow{2}{*}{$\frac{\text { Baik }}{\%}$} & & & \\
\hline & $\mathrm{N}$ & $\%$ & & & $\mathrm{~N}$ & $\%$ & \\
\hline Tinggi & 24 & 70,6 & 2 & 5,9 & 26 & 76,5 & \\
\hline Sedang & 4 & 11,8 & 4 & 11,8 & 8 & 23,5 & 0,006 \\
\hline Total & 29 & 85,3 & 5 & 14,7 & 34 & 100 & \\
\hline
\end{tabular}

Berdasarkan hasil penelitian di Bangsal Rawat Inap RS PKU Muhammadiyah Yogyakarta, diketahui bahwa perawat dengan tingkat pengetahuan tinggi dengan penerapan penggunaan antiseptik dan desinfektan yang baik sebanyak 24 perawat atau $70,6 \%$, sedangkan pada perawat yang tingkat pengetahuannya sedang dengan penerapan penggunaan antiseptik dan desinfektan yang baik sebanyak 4 perawat atau $11,8 \%$. Perawat dengan tingkat pengetahuan tinggi dengan penerapan penggunaan antiseptik dan desinfektan yang cukup baik sebanyak 2 perawat atau 5,9\%, sedangkan pada perawat yang tingkat pengetahuannya sedang dengan penerapan penggunaan antiseptik dan desinfektan yang cukup baik sebanyak 4 perawat atau $11,8 \%$.

Berdasarkan hasil uji statistik antara dua variabel diperoleh nilai $p=0,006$, yang berarti nilai $p$ lebih besar dari alpha $(0,05)$ dengan demikian Ho ditolak dan Ha diterima, yang berarti ada hubungan yang signifikan antara tingkat pengetahuan perawat dengan penerapan penggunaan antiseptik dan desinfektan pada perawat sebagai upaya pencegahan infeksi nosokomial di RS PKU Muhammadiyah Yogyakarta.

Tabel 8. Distribusi Frekuensi Responden Berdasarkan Variabel Penelitian Tingkat Pengetahuan Perawat dengan Pengunaan Alat Pelindung Diri Pada Perawat di Bangsal Rawat Inap RS PKU Muhammadiyah Yogyakarta 2009

\begin{tabular}{|c|c|c|c|c|c|c|c|}
\hline \multirow{3}{*}{$\begin{array}{c}\text { Tingkat } \\
\text { Pengetahuan }\end{array}$} & \multicolumn{4}{|c|}{ Pengg.Alat Pelindung Diri } & \multirow{2}{*}{\multicolumn{2}{|c|}{ Total }} & \multirow{3}{*}{$P$ value } \\
\hline & \multicolumn{2}{|c|}{ Baik } & \multicolumn{2}{|c|}{ Cukup Baik } & & & \\
\hline & $\bar{N}$ & $\%$ & $\mathrm{~N}$ & $\%$ & $\bar{N}$ & $\%$ & \\
\hline Tinggi & 24 & 70,6 & 2 & 5,9 & 26 & 76,5 & 0.037 \\
\hline Sedang & 5 & 14,7 & 3 & 8,8 & 8 & 23,5 & 0,031 \\
\hline Total & 29 & 85,3 & 5 & 14,7 & 34 & 100 & \\
\hline
\end{tabular}

Berdasarkan hasil penelitian di Bangsal Rawat Inap RS PKU Muhammadiyah Yogyakarta, diketahui bahwa perawat dengan tingkat pengetahuan tinggi dengan penerapan penggunaan alat pelindung diri yang baik sebanyak 24 perawat atau $70,6 \%$, sedangkan pada perawat yang tingkat pengetahuannya sedang dengan penerapan penggunaan alat pelindung diri yang baik sebanyak 5 perawat atau $14,7 \%$. Perawat dengan tingkat pengetahuan tinggi dengan penerapan penggunaan alat pelindung diri yang cukup baik sebanyak 2 perawat atau $5,9 \%$, sedangkan pada perawat yang tingkat pengetahuannya sedang dengan 
penerapan penggunaan alat pelindung diri yang cukup baik sebanyak 3 perawat atau $8,8 \%$.

Berdasarkan hasil uji statistik antara dua variabel diperoleh nilai $p=0,037$, yang berarti nilai $p$ lebih besar dari alpha $(0,05)$ dengan demikian Ho ditolak dan Ha diterima, yang berarti ada hubungan yang signifikan antara tingkat pengetahuan perawat dengan penerapan penggunaan alat pelindung diri pada perawat sebagai upaya pencegahan infeksi nosokomial di RS PKU Muhammadiyah Yogyakarta.

Tabel 9. Distribusi Frekuensi Responden Berdasarkan Variabel Penelitian Tingkat Pengetahuan Perawat dengan Pembuangan Sampah Medis pada Perawat di Bangsal Rawat Inap RS PKU Muhammadiyah Yogyakarta 2009

\begin{tabular}{|c|c|c|c|c|c|c|c|}
\hline \multirow{3}{*}{$\begin{array}{c}\text { Tingkat } \\
\text { Pengetahuan }\end{array}$} & \multicolumn{4}{|c|}{ Pembuangan Sampah Medis } & \multirow{2}{*}{\multicolumn{2}{|c|}{ Total }} & \multirow{3}{*}{$P$ value } \\
\hline & \multicolumn{2}{|c|}{ Baik } & \multirow{2}{*}{$\frac{\text { Cukt }}{\mathrm{N}}$} & \multirow{2}{*}{$\frac{1}{\text { Dalk }}$} & & & \\
\hline & $\mathrm{N}$ & $\%$ & & & $\mathrm{~N}$ & $\%$ & \\
\hline Tinggi & 25 & 73,5 & 1 & 2,9 & 26 & 76,5 & 0.001 \\
\hline Sedang & 4 & 11,8 & 4 & 11,8 & 8 & 23,5 & \\
\hline Total & 29 & 85,3 & 5 & 14,7 & 34 & 100 & \\
\hline
\end{tabular}

Berdasarkan hasil penelitian di Bangsal Rawat Inap RS PKU Muhammadiyah Yogyakarta, diketahui bahwa perawat dengan tingkat pengetahuan tinggi dengan penerapan pembuangan sampah medis yang baik sebanyak 25 perawat atau $73,5 \%$, sedangkan pada perawat yang tingkat pengetahuannya sedang dengan penerapan pembuangan sampah medis yang baik sebanyak 4 perawat atau $11,8 \%$. Perawat dengan tingkat pengetahuan tinggi dengan penerapan pembuangan sampah medis yang cukup baik sebanyak 1 perawat atau 2,9\%, sedangkan pada perawat yang tingkat pengetahuannya sedang dengan penerapan pembuangan sampah medis yang cukup baik sebanyak 4 perawat atau $11,8 \%$.

Berdasarkan hasil uji statistik antara dua variabel diperoleh nilai $p=0,001$, yang berarti nilai $p$ lebih besar dari alpha $(0,05)$ dengan demikian Ho ditolak dan Ha diterima, yang berarti ada hubungan yang signifikan antara tingkat pengetahuan perawat dengan penerapan pembuangan sampah medis pada perawat sebagai upaya pencegahan infeksi nosokomial di RS PKU Muhammadiyah Yogyakarta.

\section{B. Pembahasan}

\section{1) Tingkat Pengetahuan Perawat}

Berdasarkan hasil kuesioner diketahui bahwa tingkat pengetahuan perawat di Bangsal Rawat Inap RS PKU Muhamadiyah Yogyakarta dikategorikan tinggi sebanyak 26 perawat dengan persentase $76,47 \%$. Pengetahuan adalah hasil dari tahu, dan hal itu terjadi setelah orang melakukan penginderaan terhadap suatu proyek tertentu. Penginderaan ini dilakukan melalui penglihatan, pendengaran, penciuman, rasa dan raba. ${ }^{4}$

Pengetahuan menurut The American Heritage (2004), adalah ingatan tentang material yang telah dipelajari. Meliputi kemampuan mengingat luasnya materi, dari fakta yang spesifik sampai teori yang lengkap. Pengetahuan adalah level terendah dari hasil pembelajaran dalam domain kognitif.

Seorang perawat dikatakan profesional, jika memiliki pengetahuan, keterampilan serta memiliki sikap profesional sesuai kode etik profesi. 
Pengetahuan perawat dapat terus meningkat apabila rumah sakit dapat terus meningkatkan kemampuan dengan berbagai pelatihan dan edukasi berkesinambungann bagi seluruh karyawan pada semua aspek pencegahan infeksi.

\section{2) Penerapan Cuci Tangan Pada Perawat}

Berdasarkan hasil observasi pada penerapan cuci tangan perawat di Bangsal Rawat Inap RS PKU Muhammadiyah Yogyakarta tergolong baik sebanyak 27 perawat dengan persentase $79,41 \%$. Mencuci tangan adalah kegiatan membersihkan bagian telapak, punggung tangan dan jari agar bersih dari kotoran dan membunuh kuman penyebab penyakit. Mencuci tangan dapat mengurangi pemindahan mikroba ke pasien dan menghambat pertumbuhan mikroorganisme pada kuku, tangan, dan lengan. ${ }^{1}$

Penerapan cuci tangan pada perawat tergolong baik karna didukung oleh kesadaran perawat itu sendiri dalam melindungi diri dan pasien dari bahan infeksius serta kesadaran dalam menjalankan SOP yang benar. Kebiasaan mencuci tangan perawat di rumah sakit, merupakan perilaku mendasar dalam upaya pencegahan cross infection (infeksi silang). Pengetahuan merupakan elemen yang sangat penting untuk terbentuknya tindakan seseorang. Perawat juga harus memiliki pengetahuan tentang cuci tangan dengan benar sebagai upaya pencegahan infeksi nosokomial di rumah sakit sehingga dapat meningkatkan kualitas pelayanan.

\section{3) Penerapan Penggunaan Antiseptik dan Desinfektan Pada Perawat}

Berdasarkan hasil observasi pada prosedur penggunaan antiseptik dan desinfektan pada perawat di Bangsal Rawat Inap RS PKU Muhammadiyah Yogyakarta tergolong baik sebanyak 28 perawat dengan persentase $82,35 \%$. Desinfektan adalah bahan kimia yang menghancurkan atau menginaktifasi mikroorganisme. Desinfektan dapat diklasifikasikan kedalam tingkat rendah, menengah dan tinggi. Desinfeksi adalah suatu proses untuk menghilangkan sebagian atau semua mikroorganisme dari alat kesehatan kecuali endospora bakteri.

Memecah rantai penularan salah satunya dengan tindakan aseptik yaitu penggunaan antiseptik dan desinfektan yang merupakan upaya untuk mencegah terjadinya infeksi nosokomial dengan cara membunuh bakteri jahat penyebab infeksi dan mencegah infeksi silang antara perawat dan pasien. Teknik aseptik dapat mencegah masuknya mikroorganisme kedalam tubuh, bertujuan membasmi mikroorganisme pada permukaan hidup dan benda mati dan sebagai salah satu proses pencegahan infeksi dasar.

\section{4) Penerapan Penggunaan Alat Pelindung Diri (APD) Pada Perawat}

Berdasarkan hasil observasi pada prosedur penggunaan alat pelindung diri pada perawat di Bangsal Rawat Inap RS PKU Muhammadiyah Yogyakarta tergolong baik sebanyak 29 perawat dengan persentase $85,29 \%$. Alat pelindung diri (APD) adalah peralatan atau pakaian yang didesain khusus untuk melindungi karyawan dari bahan infeksius. Alat Pelindung Diri merupakan sarana pengendali terakhir yang digunakan setelah pengendaliannya. APD ini digunakan bersamaan dengan metode pengendalian yang lain sehingga perlindungan personal akan lebih efektif. APD harus memenuhi persyaratan seperti enak dipakai, tidak mengganggu kerja, memberikan perlindungan efektif terhadap jenis bahaya. $^{2}$

Penggunaan alat pelindung diri (APD) sebagai upaya melindungi diri dari bahan infeksius dan mencegah penularaan infeksi kepada pasien perlu 
dilakukan baik saat melakukan perawatan luka juga saat kontak dengan pasien yang berisiko.

\section{5) Pembuangan Sampah Medis Pada Perawat}

Berdasarkan hasil observasi pada prosedur pembuangan sampah medis secara aman pada perawat di Bangsal Rawat Inap RS PKU Muhammadiyah Yogyakarta tergolong baik sebanyak 29 perawat dengan persentase $85,29 \%$.

Prosedur pengelolaan sampah berdasarkan standar terkait ISO 9001: 2000. Pasal 6.3, RS PKU Muhammadiyah, Yogyakarta:

a) Pemisahan sampah rumah sakit dibedakan berdasarkan potensi bahayanya:

1) Sampah umum atau domestik adalah sampah dari kegiatan rumah tangga dan kegiatan medik yang tidak berbahaya. Sampah umum antara lain: kertas, bungkus makanan, plastik, daun-daunan dan lain -lain dibuang ke tempat sampah umum atau domestik yg telah dilapisi plastik hitam

2) Sampah infeksius adalah sampah yang mengandung kuman patogen yang bisa menularkan penyakit karena telah terkontaminasi cairan tubuh pasien. Sampah infeksius antara lain: sisa operasi, sisa sampel lab, perban, pembalut, urine bag, selang infus, kateter bekas, kapas, plastik linen kotor dan lain-lain dibuang ke tempat sampah infeksius yg telah dilapisi plastik kuning

3) Sampah cytotoksis adalah sampah yang berasal dari sisa pengobatan cytostatika yang bersifat toksik, yaitu : ampul, kapas, bungkus dan semua yang tercemar obat cytostatika dibuang ke tempat sampah cytotoksis yg telah dilapisi plastik ungu.

4) Sampah benda tajam adalah sampah berupa jarum suntik, jarum infus, pisau operasi bekas dan lain-lain yang berisiko melukai petugas.

b) Incenerator adalah mesin pemusnah sampah dengan suhu tinggi.

Beberapa karakteristik sampah dalam kaitannya dengan pemilihan cara pengelolaan yang baik dan benar sebagai salah satu upaya pengendalian infeksi nosokomial. Untuk penampungan sampah dari setiap kegiatan rumah sakit, perlu ditampung dalam suatu tempat tertentu dengan cara yang benar, sebab bila tidak, akan menjadi tempat bersarangnya serangga terutama lalat. Lalat merupakan faktor potensial dalam penularan penyakit, yang dapat menjadi sumber infeksi baru di rumah sakit. Oleh karena itu, diperlukannya review terhadap prosedur sanitasi dan higiene.

\section{SIMPULAN DAN SARAN}

\section{A. Simpulan}

1) Penerapan cuci tangan perawat di Bangsal Rawat Inap RS PKU Muhammadiyah Yogyakarta tergolong baik sebanyak 27 perawat dengan persentase $79,41 \%$ serta ada hubungan antara tingkat pengetahuan perawat dengan penerapan cuci tangan perawat di Bangsal Rawat Inap RS PKU Muhammadiyah Yogyakarta dengan nilai $p=0,019$

2) Penerapan penggunaan antiseptik dan desinfektan pada perawat di Bangsal Rawat Inap RS PKU Muhammadiyah Yogyakarta tergolong baik sebanyak 28 perawat dengan persentase $82,35 \%$ serta ada hubungan antara tingkat pengetahuan perawat dengan penggunaan antiseptik dan desinfek- 
tan pada perawat di Bangsal Rawat Inap RS PKU Muhammadiyah Yogyakarta dengan nilai $p=0,006$

3) Penerapan penggunaan alat pelindung diri pada perawat di Bangsal Rawat Inap RS PKU Muhammadiyah Yogyakarta tergolong baik sebanyak 29 perawat dengan persentase $85,29 \%$ serta ada hubungan antara tingkat pengetahuan perawat dengan penggunaan alat pelindung diri pada perawat di Bangsal Rawat Inap RS PKU Muhammadiyah Yogyakarta dengan nilai $p=0,037$

4) Penerapan pembuangan sampah medis secara aman pada perawat di Bangsal Rawat Inap RS PKU Muhammadiyah Yogyakarta tergolong baik sebanyak 29 perawat dengan persentase $85,29 \%$ serta ada hubungan antara tingkat pengetahuan perawat dengan pembuangan sampah medis secara aman pada perawat di Bangsal Rawat Inap RS PKU Muhammadiyah Yogyakarta dengan nilai $p=0,001$.

\section{B. Saran}

Bagi institusi RS PKU Muhammadiyah, Yogyakarta:

1) Mengedukasi kebijakan dan prosedur pengendalian infeksi terhadap semua staf medis.

2) Membuat mekanisme tentang pengetahuan, sikap, dan perilaku perawat untuk menjalankan SOP dengan baik dan benar.

3) Memberi reward dan punisment bagi perawat yang menjalankan SOP dengan baik.

\section{DAFTAR PUSTAKA}

1. Utama, H. W., Infeksi Nosokomial: http//klikharry.wordpres.com, diakses tanggal 4 Maret 2008, Yogyakarta. 2006

2. Patricia A. Dempsey \& Arthur D. Dempsey, Riset Keperawatan, Penerbit Buku Kedokteran, EGC, Jakarta. 2002

3. PKU, Pedoman dan Petunjuk Teknis Pengendalian Infeksi Nosokomial, RSU PKU Muhammadiyah, Yogyakarta. 2002

4. Notoadmodjo, S., Pendidikan dan Perilaku Kesehatan, Rineke Cipta, Jakarta. 2003 